\title{
Teaching "Species"
}

\author{
Mark W. Ellis • Paul G. Wolf
}

Published online: 19 December 2009

(C) Springer Science+Business Media, LLC 2009

\begin{abstract}
A clear understanding of the term "species" is fundamental to the subject of evolution. However, introductory textbooks often fail to address this topic until one of the later chapters, after having used the term species in all preceding chapters. Furthermore, definitions of terms critical to a clear understanding of this subject are often vague or absent in chapters on species concepts. We feel the popular notion of a "species problem" has been unnecessarily inflated by this less-than-effective educational approach. Clearly addressing this essential subject at the beginning of a course on evolution will prepare students to learn the details and complexities of evolution. Here we provide the background for an alternative approach to this foundational topic, followed by an outlined lesson plan. We emphasize early introduction of this subject in texts and courses using unambiguous terminology and including the historical development of species concepts.
\end{abstract}

Keywords Class · Individual · Natural theology · Species concept $\cdot$ Species category Taxonomy

\section{Introduction}

The subject of species was not a matter of debate when Carolus Linnaeus (1753) codified the taxonomic categories in the eighteenth century. Yet the widely accepted species concept of the time was faulty-a pre-Darwinian view of species as fixed and eternal entities. After Darwin published

M. W. Ellis $(\bowtie) \cdot$ P. G. Wolf

Department of Biology, Utah State University,

5305 Old Main Hill,

Logan, UT 84322, USA

e-mail: mwe.sci@gmail.com his Origin of Species in 1859, most scientists became convinced that species evolve, and the static species concept was largely abandoned. This recognition, however, launched a debate within the scientific community over the correct species concept, and a significant "species problem" was born. Although our knowledge of evolutionary processes has increased dramatically in the last 150 years, species concept debates have intensified rather than subsided. In spite of this apparent intractability, we feel that a good deal of the species problem would be eliminated with a more effective approach to teaching about species at the high school and college levels.

Our goal in this article is to provide the background necessary for a more effective approach to teaching about species - as taxa, as a category, and as a concept. We hope to clarify the subject for instructors and textbook authors so they can present it to students in a way that will serve those who will specialize in natural science as well as those who will not. To do this, we first define the associated terms, which are often confused and misused. We then provide a brief history of the evolution of species concepts to clarify the bases for current ones and to prevent repetition of past mistakes. Next, we address more recent debates about the best species concept and suggest a solution. Finally, we outline a lesson plan that will provide students with a clearer understanding of species as fundamental units of eukaryotic evolution.

\section{A Hierarchy of Species Terms}

The term "species" can refer to: (1) a species taxon - that is, a particular species found in nature (e.g., Puma concolor or Acer grandidentatum); (2) the species category, whose membership is composed of all of the species taxa; or (3) a species concept, which defines the species category. A lack 
of specificity regarding these three terms results in confusion, unnecessarily amplifying debates over the best species concept. Therefore, we begin by examining these terms more closely.

Species Taxa A species taxon (plural taxa) is simply a named species (e.g., Homo sapiens). In this article, we will use the unqualified term species to refer to one or more species taxa. Species, unlike taxonomic categories or higher taxa, can be located in space and time, and each has a function - to evolve. Every species is a real entity-a cohesive unit composed of interacting parts (organisms). Furthermore, each species evolves as a unit. As a result, each species changes over time and eventually becomes extinct or speciates.

The Species Category The species category is a rank in the hierarchical system codified by Linnaeus (1753) - one of the seven to ten major taxonomic categories (kingdom, phylum, class, order, etc.), which are often further divided (e.g., subfamily or subspecies). The members of each taxonomic category are particular taxa at that taxonomic level. For example, the kingdom category is composed of all the described biological kingdoms (Animalia, Plantae, etc.), while the genus category contains all described genera, and the species category contains all known species. Taxonomic categories are abstract constructs aimed at organizing the diversity of life (Dobzhansky 1935).

Species Concepts By broadly defining the species category, a species concept defines the nature of any and all species. Species concepts have a long history with many versions and incarnations, some of which have coexisted as competing concepts. Although many have been promoted as the best by their authors (see Slobodchikoff 1976; Claridge et al. 1997; Wheeler and Meier 2000; Coyne and Orr 2004), the following overarching concept subsumes most of those without contradicting them: a species in nature is composed of organisms in one or more populations that together form a cohesive, reproductive unit - a separate lineage on its own evolutionary trajectory (Simpson 1951; Hennig 1966; Wiley 1978; Wiley and Mayden 2000; Ghiselin 2002; de Queiroz 2005; Rieseberg et al. 2006). This primary species concept provides the necessary and sufficient traits required of species for membership in the species category.

\section{The Unique Nature of Species}

Species are often treated like higher taxa, differing in rank only, yet higher taxa are fundamentally different. For instance, the members of a family are genera that share a common ancestor; but those genera do not interact as a family unit because no biological processes unite them. They are not unified by location or time or function. One cannot point to the order Arthropoda because their members have no common location in space; and with both extinct and extant members, Arthropoda share no location in time. Higher taxa are convenient concepts to categorize related taxa. Species, however, are not concepts - they are very different entities indeed.

Species are individuals and fundamental units of evolution (Ghiselin 1966, 1974; Hennig 1966; Hull 1976; Eldredge 1985; de Queiroz and Donoghue 1988; Ridley 1989; Mayr 1996; Coleman and Wiley 2001; Crane 2004; Rieppel 2009). Individuals can be located in both space and time, and they are composed of parts (rather than members) that function as a unit. The parts of a species (organisms) interact to form a unique, reproductively cohesive whole whose function is to evolve.

Like all individuals, species defy definition (Ghiselin 1974; Hull 1976) because they change over time. A mountain will lift and erode, a cicada will grow and molt, and a species will expand and evolve. Yet individuals remain identifiable over time. A middle-aged man may bear little resemblance to the dark-and-curly-haired version of his youth, but his mother will still recognize him. A species, like $H$. sapiens, changes with each new birth and death. Indeed, $H$. sapiens has changed a great deal since its inception nearly 200,000 years ago (Randerson 2003) while remaining the same species throughout. The species concept defines the nature of all species, yet no particular species can be defined because each is a constantly evolving individual.

Although the paradigm of species-as-individuals has been accepted for decades (Ghiselin 1974; Hull 1988; Coleman and Wiley 2001; Stamos 2007; Rieppel 2009), the view is not intuitively obvious because species' parts appear so loosely organized. One never sees a species in its entirety as a separate, cohesive unit (unless it is on the brink of extinction and composed of so few organisms that they can all be seen at once). At best, we might see a herd of elk or a stand of spruce. We are far more comfortable with archetypal individuals like organisms, whose parts appear tightly organized into single, recognizable units. But relative distances are a matter of perspective. The parts of an atom have relatively vast distances between them, as do the parts of a molecule, a species, or a solar system. What they all have in common are mechanisms that organize their parts into cohesive wholes - the parts of an atom by the electromagnetic and nuclear forces, the parts of a molecule by covalent and hydrogen bonds, the parts of a species by sex, and the parts of a solar system by gravity.

The paradigm of species as eternal classes, with each organism as a representative member rather than a part, spanned some 2,500 years. Yet organisms are no more instances of their species than leaves are instances of a tree. 
Organisms cannot represent their species because they cannot evolve. In spite of these evident facts, the millennial concept of species as definable classes still lingers, culturally entrenched and not easily relinquished. A brief review of the history of species concepts will reveal why such confusion remains.

\section{The History of Species Ideas}

The history of our evolving understanding of species can be broken down into two major time periods. The first was a prolonged period in which species were viewed as eternal entities. In this regard, each species was considered to be a definable class of representative organisms. Although incorrect, this consistent and uncontroversial viewpoint was the perceived wisdom for well over 2,000 years until 1859 when Darwin presented his far more accurate theory of evolving species. Yet the post-Darwinian phase has been beset by controversy and unending debates about the true nature of species.

\section{The Pre-Darwinian Species Concept}

From the pioneering philosophers of ancient Greece and Asia Minor came two competing theories: a rational view of species as changing entities versus a mystical view of species as permanent entities. Eventually, the latter prevailed. The static species concept achieved a level of unquestioned certainty from its connection to giants of intellectual thought and its eventual adoption by political and religious institutions. Yet the ascendance of this mystical idea was largely an accident of history rather than a natural outcome of prescientific cultures.

A secular school of philosophy emerged in Ionia on the west coast of Asia Minor around $600 \mathrm{BCE}$, established by the astronomer and mathematician Thales (640-550 BCE). The school promoted rational approaches to cosmic questions (Durant 1953; Fuller and McMurrin 1957; Green 1973), a philosophy initiated by Thales, who proposed natural explanations for earthquakes, volcanic eruptions, solar eclipses, and other cosmic mysteries (Mayer 1950). Thales' student, Anaximander (610-546 BCE), addressed the origin and diversity of life, arguing that life was first formed in the sea but was driven onto land as the waters receded, with organisms developing the ability to breathe air (Mayer 1950; Popkin et al. 1999). Thus, our modern understanding of species evolving in response to environmental change has an ancient origin, provided by Anaximander over 2,500 years ago.

Had the relative freedom of ideas continued unhindered in Ionia, scientific progress would have inevitably opened the door for someone like Darwin to pass through considerably earlier than it did. But occupation by tyrannical regimes limited free inquiry, and by 494 BCE, many of the philosophers trained in this tradition had dispersed to other regions (Mayer 1950). Although the Ionian school's naturalistic approach to reality provided prescient views of matter, life, and the cosmos, its influence on the development of science would eventually be erased by the philosophy of the Socratic school, largely due (surprisingly) to Pythagoras of Samos.

Pythagoras (582-507 BCE) is justly remembered for his contributions to mathematics, but he also played a critical role in establishing the static species concept. Born on the Ionian peninsula, Pythagoras fled to southern Italy and started a communal school whose members made important advances in mathematics (Jones 1969b). The Pythagoreans were so enamored with numbers that they viewed formulas as mystical abstractions controlling reality-from objects to justice, morality, and the origin of the universe (Jones 1969b; Dudley 1997). This mix of reason and mysticism included the Pythagorean theorem, the pseudoscience of numerology, and fantasies of out-of-body travel (Serafini 1993; Dudley 1997). Their ideas would eventually reach Plato in a remarkably roundabout way, providing Plato with the fundamental element of his own developing philosophy-a philosophy that would influence western thought for millennia and would establish the static species concept.

The Athenian philosopher Plato (428-348 BCE) developed some of his views under the tutorship of Socrates. Forced to flee Athens at age 28 after his revered teacher was executed, Plato spent 12 years in exile, learning about social, political, and philosophical ideas in other cultures. While visiting one of the last remaining Pythagorean schools (Mayer 1950; Fuller and McMurrin 1957), he saw in their formulaic mysticism a conceptual escape from a world that appeared to be in flux. Plato, who was not a fan of change, felt that without eternal certainties, knowledge would be impossible (Keyt 1969). To provide certainty and permanence to his vision of the universe, he argued that all physical objects are perishable replicas that spring from unchanging, eternal, perfect forms (Green 1973). Although organisms change over time as they develop, age, and deteriorate, their ideal forms remain eternal. This mystical view portrayed each species as a class of imperfect instances (the organisms) derived from an eternal ideal form by which the species would be defined. Furthermore, these perfect forms were not accessible by studying their imperfect replicas here on earth. In Plato's view, only philosophers have the training and intuition to examine such abstractions (Jones 1969a).

Neither Plato nor his teacher Socrates were interested in hands-on science, focusing instead on morality, virtue, politics, and philosophy. However, Plato's student, Aristotle (384-322 BCE), sought reality in living samples, arguing 
that Plato's mystical forms were found within the objects themselves, thus encouraging the study of earthly things (Jones 1969a). Aristotle's promotion of science did not, however, change the prevailing view of species as static entities. On the contrary, his success as a scientist and brilliance as a logician lent credibility to the faulty Platonic view of species as definable and unchanging classes.

Although there were classical philosophers who sought answers without resorting to mysticism (e.g., Heraclitus of Ephesus, Empedocles of Sicily, Democritus of Thrace, Epicurus of Samos, Aristarchus of Samos, Eratosthenes of Alexandria, and Lucretius of Rome), their more rational ideas did not gain political traction. Instead, the accidents of history enabled the mysticism of Pythagoras, modified by Plato, to gain ascendancy via adoption by the state of Rome (Popkin et al. 1999). In the early Common Era, Saint Augustine merged Platonic philosophy with Christian theology, providing scriptural dogma with intellectual force (Gilson 1955). This political and theological nexus would entrench the static species concept for centuries.

Saint Augustine of Hippo (354-430) was a religious philosopher who, like Plato, abhorred change (Outler 2006). He infused Christianity with a modified Platonism by interpreting Plato's neutral, perfect forms as the hand of God. Augustine argued that the degree of a creature's imperfections was equal to its separation from God. This transformation of Plato's philosophy grounded species stasis in spiritual authority and divine creation. This synthesis of classical philosophy and early Christian theology presented a powerful belief system that went unchallenged until civilization's intellectual emergence from the Middle Ages.

Saint Thomas Aquinas (1225-1274), like Augustine, developed a syncretic theology that would become the prevailing wisdom and continue the static species concept; but unlike the Augustinian synthesis, this new approach would advance scientific research. Aquinas adored the natural world and found much to be admired in the scientific approach of Aristotle (Mayer 1950; Popkin et al. 1999). To blend Aristotelian philosophy with Christianity, Aquinas argued that philosophy manages things that can be proved empirically, while religion deals with that which requires faith (Jones 1969a). This creative approach to science and faith provided a noncombative worldview that opened the door to research by devout Christians and kickstarted a revolution in science. Aquinas called this syncretic vision natural theology, and its goal was the demonstration of God's existence through the illumination of creation via scientific research. Natural theology helped dissolve the domination of orthodoxy and catalyze a tempo of discovery that broke the intellectual stagnation of the Medieval period. But natural theology's acquiescence to free thought would be the agent of its own undoing (Crombie 1967) as its practitioners unerringly paved the road to the Darwinian revolution.

For a time, natural theology helped fortify and extend the continuous thread of species fixity-a view that had, by the thirteenth century, been a constant for well over a thousand years. With each incarnation of the Pythagorean conception of the permanence behind all things (via Plato, Aristotle, Augustine, and now Aquinas), the concept of species stasis was preserved, etching it as a normative viewpoint across cultures and time. But natural theology opened the Pandora's box of scientific inquiry.

Many devout natural theologians eagerly sought to uncover the details of divine creation. The Franciscan monks Roger Bacon (1214-1294) and William of Ockham (1288-1348) helped develop the scientific method (Fuller and McMurrin 1957; Popkin et al. 1999). The priest and biologist John Ray (1628-1705) promoted the nobility and sanctity of science, conducted groundbreaking scientific research, and did early work in taxonomy (McMahon 2000). The Swedish physician, botanist, and pioneering taxonomist Carolus Linnaeus (1707-1778) furthered the work of Ray, codifying the field of taxonomy and expanding our view of species diversity (Stace 1992). The courage, intelligence, and creativity of a long list of religiously devout luminaries of science-including Galileo Galilei, Robert Boyle, Nicholas Steno, Sir Isaac Newton, James Hutton, and Thomas Malthus-toppled many of the old ideas in medicine, cosmology, physics, and geology. Yet the dogma of species fixity persisted. This errant concept, so deeply rooted in Western philosophy and creation myths, held the field of biology back while the other scientific fields leapt forward (Hull 1965). Charles Darwin would finally provide the keys to understanding and accepting the reality of evolving species, breaking the millennial stranglehold. He would do this by standing on the shoulders of natural theologians.

\section{Species Concepts since Darwin}

By the middle of the nineteenth century, important discoveries by natural theologians had accumulated to a point that many of the old ideas based on religious dogma were straining at their leashes. Clearly, the earth was far older than the alleged $\sim 6,000$ years since the beginning of the Biblical creation, and fossils were now recognized as evidence of extinct species. Furthermore, stratigraphic successions of fossilized faunal groups demonstrated that not all species had come into being at the moment of creation (Koutsoukos 2007).

Evolution had been in the air in the eighteenth and nineteenth centuries in one form or another, promoted by various theorists including Pierre Maupertuis, GeorgesLouis Leclerc, Darwin's grandfather Erasmus Darwin, Jean- 
Baptiste Lamarck, Étienne Geoffroy Saint-Hilaire, Robert Grant, and Robert Chambers. Yet without a thoroughly documented and widely accepted theory, complete with one or more viable mechanisms, none of these respected names in science effectively dislodged creationist views and the static species concept, nor did they gain serious consideration by the wider scientific community (Provine 1982; Richards 1992).

Charles Darwin, originally a natural theologian himself, embarked on his trip aboard the HMS Beagle well prepared to study natural history, having read (or would soon read) the important ideas in related fields of science. Although proponents of biological evolution had yet to demonstrate a functional mechanism, the dramatic variation and sheer numbers of newly discovered species and fossils had become very difficult to explain without such a theory. After returning from his voyage, Darwin pieced together many lines of evidence (fossils, geology, morphology, biogeography, breeding experiments, etc.) along with a detailed model incorporating exponential reproduction, limited resources, competition, and the mechanism of natural selection of heritable traits (Darwin 1859).

After Darwin presented his richly supported case in his 1859 publication Origin of Species, the bulk of the scientific community rapidly accepted his theory (Gregory 2008). Many of Darwin's contemporaries, including T. H. Huxley, were so struck by the theory's simplicity and rationality that it freed them from the dilemma of choosing between insufficiently supported evolutionary hypotheses (Durant 1953; Provine 1982). Within 15 years, this paradigmatic shift was complete (Mayr 1991; Stamos 2007). Yet during the same period, a contentious debate developed regarding the details of speciation (Provine 1971). Rather than settling the question of the species concept, this first rational and supportable theory of evolution gave birth to a contentious and evolving debate that came to be known as the species problem.

In Darwin's view, the evolutionary process was exceedingly gradual (and he had his supporters). However, some contemporaries considered the process to be one of sudden change (termed saltation) between long periods of stasis (Provine 1971; Bowler 1988). Those who subscribed to speciation by saltation, with its modified form of the static species concept, included Thomas H. Huxley ("Darwin's bulldog"), Francis Galton (a brilliant scientist, admirer, and cousin), and the paleontologist and early Darwin supporter, Othniel C. Marsh (Provine 1971; Bowler 1988). Still other supporters of evolution strayed far from Darwin's theory of a branching bush with a progressive view of evolution directed toward $H$. sapiens at the pinnacle of a very linear tree. These progressionists (who envisioned humans as evolution's ultimate end product) included Earnst Haekel and Robert Chambers (Bowler 1988). With Darwin's most admiring supporters debating the most important details of his theory (a majority of whom still viewed species as fixed classes), consensus on a species concept did not approach resolution, and the influence of species stasis remained.

At the time of Darwin's death in 1882, hundreds of articles on evolution had been written in response to his theory (Provine 1982). Although biological evolution had become an accepted scientific theory, the majority of biologists questioned the validity of natural selection, and by the turn of the century, Darwin's view of gradual evolution had largely been supplanted by saltation. The rediscovery of Mendel's research by Hugo De Vries in 1900 gave saltationists added leverage, since they felt mutations provided the mechanism for sudden evolutionary leaps, and De Vries' mutation theory posited speciation could even occur in a single jump. These so-called Mendelians were opposed by the Darwinians, including Karl Pearson and W. F. R. Weldon (Provine 1971).

The biometric approach of Darwinian gradualists began to illuminate the effects of gene flow, genetic drift, and the Mendelian foundation for continuous phenotypic variation, leading to the demise of saltationism and its overemphasis on mutation. Subsequently, the Modern Synthesis of Mendelian genetics and Darwinian evolution (Provine 1971; Stamos 2007) brought a very brief period of relative consensus to the species problem by the 1940s. Dobzhansky's (1937) Genetics and the Origin of Species established the Modern Synthesis, and both Dobzhansky (1935) and Mayr (1942) provided the broadly accepted biological species concept (BSC) based on reproductive isolation. Yet, as Mayr pointed out, taxonomists at that time still held static views of species while paradoxically supporting the theory of evolution. Decades later, the field of taxonomy (in its incarnation as phylogenetic systematics) would become the cutting edge of evolutionary biology. In the 1940s, however, the delusion of species stasis remained a cultural phenomenon that prevented a broad recognition of species as dynamic, evolving individuals.

By 1951, George Gaylord Simpson was developing the evolutionary species concept, which posited that each species in nature was "a lineage... evolving independently of others, with its own separate and unitary evolutionary role and tendencies." Simpson was looking for an overarching definition that would avoid competition with other species concepts, and he felt the criterion of reproductive isolation was an unnecessary requirement given that many species, which might otherwise interbreed, had achieved the necessary separation to evolve independently. The disagreement between Mayr and Simpson launched a round of species-concept debates among evolutionary biologists that has yet to subside. Instead, it has accelerated (Hey 2006). 
Most of today's competing species concepts are operational (Mayden 1997, 1999) in that they suggest empirical methods of species discovery or delineation. Individually, operational concepts fail to recognize all species that, along with asexual entities and the ever-present percentage of unassigned individuals, represent the length and breadth of biodiversity. For instance, under the BSC, species status is achieved only when a reproductive barrier has evolved, which is not a requirement of the Ecological Species Concept (EcSC Van Valen 1976). The EcSC, on the other hand, requires that species be lineages that are ecologically distinct, which is not a requirement of the BSC. Demonstrating either reproductive or ecological isolation for a group of populations will strongly indicate their status as a species. Both concepts are valuable, yet neither is an ideal approach in all circumstances. Furthermore, demonstrating evidence for a species under more than one operational concept provides corroborative support. These operational species concepts should be viewed not as competing definitions that falsely inflate the so-called species problem, but as compatible concepts consistent with an ontological understanding of species that has been in effect for decades.

A proliferation of species concepts demonstrates the positive impact of evolutionary theory. Rather than posing a problem, multiple operational species concepts are a natural outcome of the development of new technologies and the impact of the results those technologies provide. The zeal of specialists has, however, led to the mistaken idea that operational concepts should supersede one another rather than coexist as consilient evolutionary tools for clearly describing one's approach to research. An overarching nonoperational species concept subsuming valid operational concepts provides a solution to this debate. Mayden (1997, 1999) proposed just such a hierarchy of concepts. His nonoperational, primary species concept-essentially the combined evolutionary species concepts of Simpson (1961) and Hennig (1966) paraphrased in the Species Concepts subsection above-recognizes species as individuals and is neither biased nor limited by the types of eukaryotic taxa examined nor the technologies used in identification.

\section{A New Educational Approach to the Subject of Species}

In many textbooks on evolution, the subject of species concepts is presented in one of the later chapters. Freeman and Herron (2007) do not address species concepts until chapter 16 of their 20-chapter textbook. The subject is tackled in part four of five in Ridley (2003), chapter 11 of 12 in Stearns and Hoekstra (2005), part five of six in Hall and Hallgrimsson (2007), chapter 22 of 26 in Barton et al. (2007), and chapter 17 of 23 in Futuyma (2009). The approaches in these texts tend to perpetuate the species problem by leaving critical terms undefined while highlighting the competition between various operational concepts.

In our view, a chapter on the subject of species should be presented as an essential lesson in one of the earliest chapters (ideally immediately following an introductory chapter presenting the discoveries of Darwin and Mendel). A well-laid-out chapter, lecture, or series of lectures for this fundamental subject should include three components: (1) a broad history detailing our evolving understanding of species found in nature, (2) a clear explanation of the associated terminology, and (3) a general discussion of species concepts. Here we outline a possible approach, which can be expanded or reduced based on the time available, scholastic level, and goals of the course.

Day One:

I. (10 minutes): Introduction

A. Introduce the concept of species by engaging the students, asking them to name species they find interesting, unique, closely related, distantly related, etc. The goal is to have them connect with their own understanding of what species are.

B. Show images of various species, with both common names and scientific names. Discuss the value of scientific names - their worldwide universality.

C. It is useful to compare species that are closely related yet distinct (such as species of marmoset), clearly related yet distantly (e.g., hummingbirds and ostriches), very dissimilar but surprisingly related (e.g., hyrax and elephant), and species that appear similar or the same due to convergent evolution (mimics such as monarch and viceroy butterflies or the marsupial squirrel glider, Petaurus norfolcensis, of Australia, and the placental northern flying squirrel, Glaucomys sabrinus, of temperate North America).

II. (5 minutes): Explain that species have been recognized as separate entities by all cultures

A. Provide images of various species that demonstrate the need for accurate identification

B. Cultures relied on accurate identification for survival (taxonomy is the oldest profession!):

1. Many species illustrate this, such as harmless king snakes and similarly colored venomous coral snakes and poisonous plants and fungi that resemble edible varieties.

III. (20 minutes): Discuss the historical development of species concepts as a means of introducing the related 
terminology and to provide an interesting and entertaining arc to grab student interest:

A. Start with the Ionian philosopher Pythagoras of Samos, whom students might assume to be a paragon of rationality given his penchant for mathematics and proportion (e.g., the Pythagorean Theorem). However, Pythagoras and those in the Pythagorean movement were also steeped in occult rituals and pseudoscientific beliefs. They felt that all reality was governed by eternal mathematical formulas.

B. Briefly discuss the Ionian school of Miletus, whose theorists (unlike the Pythagoreans) sought rational explanations to earthly and cosmic phenomena (mention Thales and Anaximander).

C. Describe the early concepts of evolution held by Anaximander (610-546 BCE).

D. Explain that it was Plato's philosophy-an outgrowth of Pythagorean mysticism - that led to the establishment of the nonevolutionary idea of species as eternal entities, which became the prevailing species concept for over 2,000 years. This scientific theory became incorporated into religious doctrine (by St Augustine in the fourth and fifth centuries, and modernized by St Thomas Aquinas in the thirteenth century), giving it added authority and longevity.

E. Discuss the emergence of Natural Theology and the remarkable scientific contributions by its practitioners who did groundbreaking science in their quest to uncover the details of God's creation (e.g., Galileo Galilei, Johann Kepler, John Ray, Isaac Newton, Carolus Linnaeus, and Gregor Mendel).

F. Briefly discuss the taxonomic system codified by Linnaeus (with all taxa, including species).

G. This is a good time to clarify the three important terms involving species: (1) species taxa as codified by Linnaeus; (2) the species category, whose membership includes all the species; and (3) the species concept, which defines the species category and the nature of all species within it. At the time of Linnaeus, everyone still viewed all species as unchanging. Thus, the static species concept defined species as eternal entities, each defined by a set of necessary traits.

IV. (15 minutes): Discuss Darwin's revolutionary idea. Since the students should already be familiar with Darwin's and Mendel's discoveries, this can be a very brief recap, emphasizing instead the impact on the scientific community rather than on the details of evolutionary change.

A. Begin by briefly discussing earlier proponents of evolution (Erasmus Darwin, Jean-Baptiste Lamarck, etc.), and explain that their ideas failed to gain wide acceptance because they lacked a well-supported mechanism for evolutionary change.

B. Explain the impact of Darwin's (1859) publication of Origin of Species.

1. Remind them of Darwin's argument that natural selection provided the mechanism for evolutionary change.

2. Mention the extensive evidence he provided: fossils, patterns of variation in both humanselected and wild species, and patterns suggesting branching lineages across space and time.

3. Emphasize what a radical challenge this was to the 2,500-year-old static species concept, since evolution by natural selection suggested species were not static at all but constantly changing, evolving, entities.

4. If you have time, you might mention some comments from the last important scientists who remained supporters of the static species concept (e.g., Louis Agassi and Lord Kelvin) to further illustrate the challenge Darwin faced.

Day Two:

I. (15 minutes): Discuss Darwin's ideas and the two opposing species concepts it launched.

A. Once evolution was accepted, many tried to combine the static species concept with the new theory of evolution, arguing that species would have long periods of stasis and then experience sudden evolutionary change in a process called saltation. Others, including Darwin, considered evolution an imperceptibly slow process called gradualism.

B. When Mendel's research was rediscovered, the saltationists felt vindicated, arguing mutation was the mechanism of sudden evolutionary change. But the gradualists felt that large mutations were nearly always deleterious while selectively advantageous mutations would be too rare to be important.

C. Explain that eventually careful studies demonstrated that both Mendel's and Darwin's discoveries worked together to explain gradual evolutionary change, including continuous quantitative variation, leading to an end to the saltationist concepts 
and culminating in the Modern Synthesis of evolutionary theory.

II. (10 minutes): The Modern Synthesis advanced evolutionary biology, leading to evolutionary concepts of species.

A. Even after the static species concept was abandoned, remnants remained

1. Species were still thought of as classes whose members were individual organisms.

2. Organisms were classified as members of a species by a set of required traits.

3. Species were often defined by a type specimen, suggesting each species was a fixed type.

B. However, since species are evolving entities, with only a subset of organisms contributing their traits to each new generation, a species never remains quite the same and can therefore never be defined

1. With the development of protein and DNA analytical techniques, it became even more apparent that species are constantly changing, as the fittest members successfully reproduce and pass on their genetically heritable traits.

2. The gene pool for a species will change to some degree every generation. It even changes with each birth and death.

C. By the 1960s and 1970s, researchers were finally beginning to relinquish the ancient idea of species as definable classes, recognizing them instead as individuals.

III. (10 minutes): Species taxa versus higher taxa

A. Describe the Linnaean system of taxonomic categories and the taxa within them

1. Give the Linnaean hierarchy as often used today

a) Domain, kingdom, phylum, class, order, family, genus, species

2. Provide examples of species and the higher taxa within which they are organized

B. Explain how species (as objective individuals) are radically different than higher taxa (which are historical entities arbitrarily chosen to categorize species)

IV. (15 minutes): Evolutionary species concepts.

A. It became apparent that all species are the culmination of evolutionary lineages. This led to the development of new species concepts that recognized species as evolving individuals.

1. Many species concepts suggested a method of discovery (genetic, ecological, morphological, etc.)
2. These operational concepts were backed by different analytical methods

B. Although many concepts were promoted as superior to the rest, their operational approaches to species recognition limited the scope of each. They are, therefore, secondary species concepts that should be considered complimentary rather than exclusive.

C. Give the primary species concept that defines the species category:

1. A species in nature is composed of organisms in one or more populations that together form a cohesive, separately evolving reproductive unit.

a) There may be a great deal of diversity, or relatively little, within any single species, but each evolves on its own, with little or no input from other species.

b) Few isolating mechanisms are foolproof, from geographic isolation to chromosomal incompatibility. But with enough reproductive isolation, a reproductively cohesive set of populations will diverge as a unit, becoming increasingly unique.

c) Although no species can be defined since no set of traits will permanently remain in an evolving species, the shared traits of the organisms that make up a species at any point in time can be analyzed, and the findings enable researchers to delineate the geographical boundaries of a species and identify their component organisms.

d) Note that operational species concepts would be secondary to this primary concept

\section{Conclusion}

We are currently leaving students unprepared for the details of evolution by failing to provide them with a general understanding of species at the beginning of biology textbooks and courses. Offering them incomplete details of the subject late in the course only exacerbates their confusion.

Students will benefit from a summarized account of the long and fitful history of species concepts. Not only enlightening scientifically, it is an intriguing story about species and human nature that can capture students' attention. Understanding this history will impart a measure of inoculation against repeating past mistakes and misconceptions, which are in large part the nature of what some consider the species problem today (Wiley 2002).

Understanding the terminology inherent to the subject of species provides an additional line of defense against 
falling prey to vague assertions of a species problem. By grasping the differences between species as either individual entities in nature, the taxonomic category, or concepts defining the species category and its members, students will be better equipped to address the finer points of evolutionary theory. Furthermore, they will have the background necessary to demand clarity from others so that a meeting of minds on the subject is possible. Students of biology versed in all three components of this subject-history, terminology, and concepts-will be prepared to pursue challenging questions of taxonomy and systematics and the relationship of those questions to all fields of biologyfrom ecology to genomics to conservation.

Because species are what in fact evolve, the three components of this subject should be addressed at the beginning of any course on evolution. Students will then understand that species are real entities and fundamental evolutionary units, and only then will they be prepared to tackle the broader subject of evolution.

Acknowledgments We thank two anonymous reviewers for valuable suggestions. We also thank Karen Mock for helping launch this effort, and Leigh Latta for his ideas and support.

\section{References}

Barton NH, Briggs DEG, Eisen JA, Goldstein DB, Patel NH. Evolution. Woodbury: Cold Spring Harbor Laboratory Press; 2007.

Bowler PJ. The non-Darwinian revolution. Baltimore: The Johns Hopkins University Press; 1988.

Claridge MF, Dawah HA, Wilson MR. Species: the units of biodiversity. New York: Chapman \& Hall; 1997.

Coleman KA, Wiley EO. On species individualism: a new defense of the species-as-individuals hypothesis. Philos Sci. 2001;68:498 517

Coyne JA, Orr HA. Speciation. Sunderland: Sinauer Associates, Inc.; 2004.

Crane JK. On the metaphysics of species. Philos Sci. 2004;71:156-72.

Crombie AC. Medieval and early modern science, volume I. Cambridge: Harvard University Press; 1967.

Darwin CR. On the origin of species by means of natural selection, or the preservation of favoured races in the struggle for life. London: John Murray; 1859.

de Queiroz K. Different species problems and their resolution. Bioessays. 2005;27:1263-9.

de Queiroz K, Donoghue MJ. Phylogenetic systematics and the species problem. Cladistics-the International Journal of the Willi Hennig Society. 1988;4:317-38.

Dobzhansky T. A critique of the species concept in biology. Philos Sci. 1935;2:344-55

Dobzhansky T. Genetics and the origin of species. New York: Columbia University Press; 1937.

Dudley U. Numerology: or, what Pythagoras wrought. Washington DC: The Mathematical Association of America; 1997.

Durant W. The story of philosophy. New York, NY: Simon and Schuster; 1953.

Eldredge N. Time frames. New York: Simon and Schuster; 1985.

Freeman S, Herron JC. Evolutionary analysis. 4th ed. Upper Saddle River: Prentice Hall; 2007.
Fuller BAG, Mcmurrin SM. A history of philosophy. 3rd ed. New York, NY: Henry Holt and Company; 1957.

Futuyma DJ. Evolution. 2nd ed. Sunderland: Sinaurer Associates, Inc.; 2009.

Ghiselin MT. On psychologism in the logic of taxonomic controversies. Syst Zool. 1966;15:207-15.

Ghiselin MT. A radical solution to the species problem. Syst Zool. 1974;23:536-44.

Ghiselin MT. Species concepts: the basis for controversy and reconciliation. Fish Fish. 2002;3:151-60.

Gilson E. History of Christian philosophy in the middle Ages. New York, NY: Random House; 1955.

Green P (1973) A concise history of Ancient Greece to the close of the classical era. Thames and Hudson

Gregory T. Evolution as fact, theory, and path. Evolution: Education and Outreach. 2008;1:46-52.

Hall BK, Hallgrimsson B. Strickberger's evolution. Boston: Jones and Bartlett Publishers; 2007.

Hennig W. Phylogenetic systematics. Urbana, IL: University of Illinois Press; 1966.

Hey J. On the failure of modern species concepts. Trends Ecol Evol. 2006;21:447-50.

Hull DL. The effect of essentialism on taxonomy - two thousand years of stasis. Br J Philos Sci. 1965;15:314-26.

Hull DL. Are species really individuals? Syst Zool. 1976;25:174-91.

Hull DL. The myth of Darwinism. Review of the non-Darwinian revolution by Peter. J Bowler. 1988;242(4886):1710-1.

Jones WT. A history of western philosophy: the classical mind. New York, NY: Harcourt, Brace \& World, Inc; 1969a.

Jones WT. A history of western philosophy: the medieval mind, volume II. New York: Harcourt, Brace \& World, Inc; 1969b.

Keyt D. Plato's paradox that the immutable is unknowable. Philos Quart. 1969;19:1-14.

Koutsoukos E. Stratigraphy: evolution of a concept. Dordrecht: Springer; 2007.

Linnaeus C. Species plantarum, 2 vols. Stockholm: Salvi; 1753.

Mayden RL. A hierarchy of species concepts: the denouement in the saga of the species problem. In: Claridge MF, Dawah HA, Wilson MR, editors. Species: the units of biodiversity. New York: Chapman \& Hall; 1997.

Mayden RL. Consilience and a hierarchy of species concepts: advances toward closure on the species puzzle. J Nematol. 1999;31:95-116.

Mayer F. A history of ancient \& medieval philosophy. New York: American Book Company; 1950.

Mayr E. Systematics and origin of species. New York, NY: Columbia University Press; 1942.

Mayr E. The ideological resistance to Darwin's theory of natural selection. Proc Am Phil Soc. 1991;135:123-39.

Mayr E. What is a species, and what is not? Philos Sci. 1996;63:26277.

McMahon S. John Ray (1627-1705) and the Act of Uniformity 1662. Notes and Records of the Royal Society of London. 2000;54:153 78.

Outler AC. Augustine: confessions and enchiridion. Philadelphia, PA: Westminster John Knox Press; 2006.

Popkin RH, Brown SF, Carr D, Copenhaver BP, Flynn TR, Makkreel RA, et al. The Columbia history of western philosophy. New York, NY: Columbia University Press; 1999.

Provine WB. The origins of theoretical population genetics. Chicago: University of Chicago Press; 1971.

Provine WB. Influence of Darwin's ideas on the study of evolution. Bioscience. 1982;32:501-6.

Randerson J. The dawn of Homo sapiens. New Sci. 2003;178:4-5.

Richards RJ. The meaning of evolution. Chicago, IL: University of Chicago Press; 1992. 
Ridley M. The cladistic solution to the species problem. Biol Philos. 1989;4:1-16

Ridley M. Evolution. Cambridge: Blackwell Publishing; 2003.

Rieppel O. Species as a process. Acta Biotheor. 2009;57:33-49.

Rieseberg LH, Wood TE, Baack EJ. The nature of plant species. Nature. 2006;440:524-7.

Serafini A. The epic history of biology. New York: Plenum Press; 1993.

Simpson GG. The species concept. Evolution. 1951;5:285-98.

Simpson GG. Principles of animal taxonomy. New York: Columbia University Press; 1961.

Slobodchikoff CN. Concepts of species. Stroudsburg: Dowden, Hutchinson \& Ross, Inc; 1976.

Stace CA. Plant taxonomy and biosystematics. Cambridge: Cambridge University Press; 1992.
Stamos DN. Darwin and the nature of species. Albany: State University of New York Press; 2007.

Stearns S, Hoekstra R. Evolution: an introduction. New York: Oxford University Press; 2005.

Van Valen L. Ecological species, multispecies, and oaks. Taxon. 1976;25:233-9.

Wheeler QD, Meier R. Species concepts and phylogenetic theory. New York: Columbia University Press; 2000.

Wiley EO. The evolutionary species concept reconsidered. Syst Zool. 1978;27:17-26.

Wiley EO. On species and speciation with reference to the fishes. Fish Fish. 2002;3:161-70.

Wiley EO, Mayden RL. The evolutionary species concept. In: Wheeler QD, Meier R, editors. Species concepts and phylogenetic theory: a debate. New York: Columbia University Press; 2000. 